\title{
PEREMPUAN DAN IPTEK
}

\author{
Sri Harini*
}

\begin{abstract}
ABSTRAK
Peranan perempuan di negara kita sekarang ini telah berkembang dengan pesat di segala bidang, termasuk diantaranya dalam pengembangan sains dan teknologi. Hal ini tidak terlepas dari jasa Raden Ajeng Kartini yang telah memeperjuangkan kesamaan hak antara laki-laki dan perempuan.

Tetapi dilain pihak harus diakui pula bahwa pada kenyataannya masih ada kesenjangan yang cukup lebar antara kelompok perempuan yang berpendidikan tinggi dengan laki-laki mengenai cara pandang tentang peranan perempuan dalam pengembangan sains dan teknologi. Bahkan lebih ekstrem lagi mengapa perempuan selalu tertinggal prestasinya dalam bidang IPTEK dibandingkan dengan laki-laki, meskipun ada beberapa prestasi perempuan dalam IPTEK yang tidak kalah dengan laki-laki.
\end{abstract}

Kata Kunci : sains dan teknologi, ilmu pengetahuan dan Teknologi.

\section{A. Pendahuluan}

Seperti kita ketahui bahwa pengembangan IPTEK adalah merupakan salah satu bagian dalam pembangunan di Indonesia. Karena IPTEK merupakan salah satu bagian yang punya peranan penting bagi kemajuan dan keberhasilan suatu negara. Dalam mengembangkan IPTEK ini sangat dibutuhkan adanya suatu kerjasama dari semua pihak baik pemerintah, swasta dan masyarakat. Hal ini sejalan dengan cita-cita dari Raden Ajeng Kartini yang telah memeperjuangkan kesamaan hak antara laki-laki dan perempuan.

Tetapi di lain pihak kebijakan IPTEK di Indonesia juga masih memarginalkan peran perempuan, hal ini karena kebijakan IPTEK yang diambil itu lebih melayani kaum kapital, sehingga nantinya laki-laki terutama perempuan jugalah yang menjadi korbannya karena sebagian besar penduduk miskin didunia adalah berjenis kelamin perempuan. Dengan kemiskinannya dan privatisasi 
pendidikan di Indonesia maka akses mereka pada pemenuhan hak dalam bidang IPTEK akan semakin jauh dari yang diharapkan.

\section{B. Keterkaitan Perempuan dengan Iptek}

Tidak benar sama sekali kalau perempuan sejak awal terasing dari dunia IPTEK, yang benar adalah perempuan secara keseluruhan tertinggal dari laki-laki dalam penguasaan IPTEK. Hanya saja, ketertinggalan ini mempunyai bentuknya sendiri-sendiri diberbagai jaman.

Dalam mengartikan ketertinggalan ini, dua aliran feminis mempunyai pandangan yang berbeda dimana aliran eko-feminis percaya bahwa ada keterkaitan antara sifat maskulin dengan teknologi sehingga otomatis melekat suatu kondisi dirnana teknologi menyebabkan dominasi laki-laki terhadap perenpuan karena. faktor patriarki ${ }^{1}$. Aliran eko-feminis ini berargumentasi dengan mengatakan bahwa itulah sebabnya laki-laki suka menguasai miture (alam atau materi) dan women (perempuan) melalui pendayagunaan teknologi yang dimilikinya. Sementara aliran feminis liberal berpendapat bahwa teknologi itu netral karena aliran ini berpendapat bahwa laki-laki dan perempuan adalah setara dan secara mendasar mempunyai kesamaan dalam hal perasaan dan rasionalitas $^{2}$. Hanya saja menurut aliran ini, potensi yang dipunyai perempuan itu tidak bisa berkembang karena gender stereotip yang melekat pada wanita dimana

\footnotetext{
${ }^{1}$ Gill \& n Grint, "The Gender-Technology Relation: Contemporary Theory and Research", (Taylor and Francis Ltd, London, 1995), 6
}

\section{${ }^{2}$ Ibid, 6}


memberikan tambahan beban yang berlebih manakala perempuan ingin mengembangkan kemampuan rasionalitasnya dalam bidang IPTEK.

Pada jaman pra-sejarah dimana hubungan. laki-laki dan perempuan didasarkan pada aliran fungsional, keberadaan dan fungsi perempuan sudah cukup bila bias melahirkan dan memelihara serta menjaga anaknya dalam tenda, sementara laki-laki harus berburu keluar untuk kelangsungan hidup keluarga itu serta untuk eksistensi dirinya. Dalam menjalankan tugas inilah laki-laki menggunakan alat bantu baik berupa, bambu yang ditajamkan, parang, tombak d11. Alat bantu tersebut (yang kemudian merupakan cikal bakal teknologi) bagi laki-laki digunakan untuk fungsi menghancurkan atau menaklukkan hewan maupun lingkungan. Sementara meskipun perempuan juga mengalami evolusi penggunaan alat-alat rumah tangga, tetapi semua bukan untuk fungsi destruktif melainkan fungsi memelihara dan merapikan sesuatu yang belakangan distereotipekan sifat-sifat yang dimiliki perempuan.

Sementara itu di awal pengembangan dunia kapital di barat, terdapat pemisahan dunia publik dan privat dimana pergeseran dunia perempuan dari keluarga ke pabrik-pabrik garmen. Hal ini mengakibatkan pembagian gender yang lebih tegas dimana laki-laki mendominasi dan menguasai teknologi ${ }^{3}$. Pembagian di negara kita saat ini masih terjadi dimana dominasi ini terlihat dari masih ditempatkannya perempuan dibidang pekerjaan yang relative lebih mudah dilakukan dan tidak membutuhkan keahlian khusus tetapi cenderung hanya

\footnotetext{
${ }^{3}$ WaJcman, “Feminism Controls Technology”, Polity, Cambridge. 1991, 21.
} 
rutinitas $^{4}$. Di bidang-bidang lainpun perempuan mengalami nasib yang serupa, hal ini karena, suatu asumsi bahwa perempuan kurang dalam penguasaan teknologi dibanding dengan laki-laki ${ }^{5}$.

Salah satu alasannya klasik yang dipakai untuk menempatkan posisi perempuan pada pekerjaan-pekerjaan yang kurang memerlukan kemampuan teknik atau analisis yang mendalam adalah dengan memanipulasi sifat-sifat yang dimiliki perempuan atau dikenal dengan stereotip gender. Tidak hanya itu, WaJcman malah mengungkapkan bahwa hal itu dikarenakan perempuan itu sendiri memberikan identitas dirinya sedemikian rupa sehingga dapat menghambat kemampuan dirinya untuk mengembangkan potensi dirinya.

Bahkan dalam bidang yang lebih canggihpun seperti computer, argumentasi bahwa perempuan berusaha mempertahankan identitasnya dalam bentuk pengingkaran terhadap potensi penguasaan IPTEK yang dimiliki perempuan itu sendiri seperti diungkapkan oleh WaJcman bahwa 'Women use their rejection of computers to assert something about themselves as women: in raecling computers they are doing femininity' Dari apa yang dikatakan WaJcman tersebut dapat dikatakan bahwa perempuan tidak menguasai komputer karena persepsinya untuk mempertahankan identitasnya kefemininenannya.

Masalah identitas sebenarnya adalah sesuatu yang yang dapat berubah. Apa yang dikatakan WaJcman dapat dievaluasi dengan persepsi yang

\footnotetext{
${ }^{4}$ Prihatinah, T.L "Feminist Analysis of Women Workers in the Export Garmen 'actories of Central Java - Indonesia", thesis S2, Universitas Murdoch, Western Australia. 1996

${ }^{5}$ Rosalind Gill dan Keith Grint, "The Gender-Technology Relation: Contemporary Theory and Research", Taylor and Francis Ltd, London. 1995, 4
} 
menguntungkan perempuan dalarn mengembangkan IPTEK, misalnya dengan mengatakan "Perempuan lebih feminin kalau dapat mengoperasikan komputer secara baik". Bahkan bukti radikal penguasaan IPTEK oleh perempuan sudah ada dimana Merie Curie mendapatkan hadiah nobel karena. menemukan elemen polonium tahun 1898 dan anaknya, Irene Juliot-Curie berhasil mendapatkan hadiah nobel kimia karena menemukan radioaktivitas buatan tahun $1935^{6}$. Dan mungkin masih banyak lagi cerita sukses dari perempuan-perempuan dalam bidang IPTEK yang belum disebarluaskan apalagi dibukukan sehingga anggapan bahwa perempuan incapable dalam bidang IPTEK perlu untuk dipertanyakan kebenarannya.

Meminjam bahasanya Rothschild (1983) bahwa perempuan-perempuan ini dalam posisi 'hidden from history' mereka tersembunyi dari sejarah. Implikasinya adalah seolah-olah perempuan tidak pernah membuat suatu prestasi yang bagus dalam bidang IPTEK karena tidak ada bukti sejarah yang mencatatnya. Permasalahan bagaimana perempuan dapat mencapai prestasi tinggi dalam IPTEK tentunya tidak semudah membalikkan telapak tangan. Tidak hanya perempuan itu harus dapat mengatasi rintangan yang bersifat internal dan eksternal. Rintangan internal ini datang dan ada dalam diri perempuan itu sendiri, contohnya kurang percaya diri, pengaturan waktu yang tidak baik d11, sementara rintangan eksternal adalah rintangan yang datang dari luar contohnya pelabelan negatif tentang sifat-sifat perempuan, lingkungan yang tidak

\footnotetext{
${ }^{6}$ Yulianto Mohsin, (terjemah), 2005, "Irene Juliot-Curie: Penemu Radioaktivitas Buatan, (Irenedoliol-Curie", Nobel Pri.:e Women in,3cience”,) oleh McGrayne, Sharon. 2005
} 
akomodatif bagi perempuan untuk maju baik yang datang dari laki-laki maupun dari perempuan lain. Sehingga satu masalah yang dihadapi perempuan, memerlukan usaha berlipat (mulliple efforls) dari perempuan untuk mengatasinya tergantung dari komplek dan simplenya kondisi perempuan.itu sendiri.

\section{Dampak Kemajuan IPTEK Terhadap Perempuan}

Setiap negara, tak terkecuali negara berkembang dalam pembangunan ekonominya di era global ini selalu bersinggungan dengan teknologi dari luar. Teknologi itu sendiri menurut United Nations Conference on Transnational Corporations (UNCTC) dapat diartikan secara sempit dan secara secara luas. Dalam arti sempit teknologi adalah "technical knowledge or know how that is knowledge related to the method and techniques production of goods and services"7. Dalam pengertian ini keahlian manusia yang diperlukan untuk menerapkan teknik-teknik itu dapat dianggap sebagai teknologi. Sedangkan secara luas teknologi meliputi barang-barang modal yaitu alat-alat, mesin-mesin dan seluruh sistem produksi yang boleh dikatakan sebagai teknologi berwujud. Sementara definisi lain menyebutkan "Technology is the activity or study of using scientific knowledge for practical purposes in industry, farming, medicine, or business". ${ }^{8}$ Karena begitu luasnya bidang yang berkaitan dengan IPTEK termasuk teknologi, maka untuk melihat dampak IPTEK terhadap perempuan harus dilihat bidang perbidang atau kasus per kasus.

\footnotetext{
${ }^{7}$ UNCTC, 1987

${ }^{8}$ Cobuild, 1989, 823.
} 
Seperti sudah dikemukakan terdahulu bahwa laki-laki mendominasi penguasaan IPTEK dibanding perempuan. Akibatnya adalah dalam mendefinisikan suatu kebijakan maka suara laki-laki itulah yang otomatis lebih mempengaruhi dalam pengambilan keputusan. Tidak jarang hal ini tidak selalu sejalan dengan kebutuhan perempuan. Seperti contoh tentang penguasaan teknologi yang diungkapkan oleh Karpf bahwa "The effect of Male control of technology and womens exclusion and alienation from it is that the technologies produced five use by women may be highly mappropriate to women's needy, and even pemicious as well as embodying male ideologies of how women should live “.

Contoh lain dalam bidang komunikasi khususnya semakin maraknya pemakaian telephone genggam (HP) yang menyebabkan perubahan relasi gender dengan dunia luar. Penelitian yang dilakukan oleh Rakow dan Navarro (1993) menyimpulkan bahwa HP bagi perempuan berfungsi sebagai alat untuk memperluas sekat-sekat kehidupan publik sehingga perempuan membawa kehidupan personal mereka ke tempat umum. Sementara buat laki-laki, HP berfungsi sebagi alat yang membawa kehidupan publik mereka kedalam kehidupan privat. Dalam kasus yang terakhir ini laki-laki dan juga perempuan dapat setiap saat menginformasikan keberadaannya ke rumah dengan sangat mudah, terlepas dari kebenaran yang disampaikan. Tanpa adanya HP ini adalah tidak bisa dibayangkan bagaimana perempuan dimasa lampau mengetahui kegiatan suaminya diluar rumah. Ini merupakan suatu bukti bahwa pengembangan teknologi dapat mempengaruhi relasi gender dan masih banyak 
lagi bukti-bukti lain yang tidak bias disebutkan satu persatu seperti penemuan microwave, mesin cuci, internet $\mathrm{d} 11$.

\section{Maskulin v.s Feminin Teknologi}

Sudah dikemukakan di muka bahwa teknologi sebagai alat bantu atau tools buat laki-laki adalah sebagai alat penghancur, meskipun hal ini masih bias diperdebatkan. Hal ini merupakan pelabelan negatif terhadap fungsi teknologi bagi laki-laki dengan mengatakan bahwa teknologi penghancur adalah sebagai maskulin teknologi. Sayang sekali beberapa perang yang melanda dunia menggunakan teknologi yang canggih untuk menghancurkan umat manusia yang lain dan ternyata dapat dikatakan "man behind the gun". Untuk itu Kaith Grint dan Steve Woolgar berpendapat bahwa dipandang dari aliran. eko-feminis maka maskulin teknologi perlu diganti dengan feminin teknologi yang lebih mempunyai sifat membangun dan memelihara. Mereka menyatakan bahwa, "If what count as femine and masculine are cultural attributes, subject to challenge and change, then replacing 'masculine' technologies with 'feminine' technologies begs the question of what precisely (and who decides what) is to count as feminine technology". 9 Disamping itu perempuan sebaiknya memilih dan mempunyai pekerjaan intelektual yang bersifat feminin atau disebut feminine intellectual work.

Sementara feminis liberal mengajukan beberapa alternatif agar perempuan tidak tertinggal dalam IPTEK, antara lain kampanye agar perempuan

\footnotetext{
${ }^{9}$ Grint, K. dan Gill, R., 1995, "The Gender-Technology Relation: Contemporary Theory
} and Research", Taylor and Francis Ltd, London. 1995, 57 
memilih profesi non iradisionil, pendidikan khusus dan training buat perempuan dalam teknologi dan kebijakan-kebijan khusus lainnya. ${ }^{10}$ Bagi perempuan sendiri, perubahan persepsi yang positif tentang keterlibatannya dalam IPTEK dapat menumbuhkan sikap yang positif bahkan dapat dijadikan model bagi generasi mendatang dalam memandang IPTEK. Universitas Pretoria melakukan hal ini dengan memberi kesempatan pada perempuan yang berhasil dalam bidang IPTEK untak menyuarakan isi hatinya. Suara perempuan tentang IPTEK khususnya sebagai seorang insinyur mengatakan bahwa profesi sebagal insinyur perempuan memiliki positif karakieristik sbb:

- Insinyur adalah pekerjaan yang menyenangkan.

- Perempuan insinyur secara alamiah adalah kreatif dan mempunyai kemandirian.

- Pekerjaan insinyur merangsang kemampuan intelektual.

- Pekerjaan sebagai insinyur mendatangkan penghasilan yang tinggi. ${ }^{11}$

Terlepas dari nuansa man informasi yang datang dari Universitas Pretoria tersebut, hal ini membuktikan bahwa ada kecenderungan global untuk mendorong perempuan lebih terlibat aktif dalam IPTEK. Hanya saja apa yang dikhawatirkan Rosalind Gill dan Keith Grint harus diperhitungkan dimana ia menyatakan bahwa, "Technologies are not neutral but gendered, and the masculinity of technologies will not be changed merely by the inclusion of more

${ }^{10}$ Grint, K. dan Gill, R., 1995, "The Gender-Technology Relation: Contemporary Theory and Research", Taylor and Francis Ltd, London. 1995, 6

${ }^{11}$ Universitas Pretoria, 2005 
women in the design process". Untuk itu perlu beberapa strategi yang harus ditempuh untuk terealisasinya IPTEK yang lebih berkeadilan gender.

\section{E. Solusi Kesenjangan IPTEK di Indonesia}

Seperti kita ketahui bahwa pengembangan IPTEK adalah merupakan salah satu bagian dalam pembangunan, maka meminjam teori gender dan pembangunannya, terdapat dua pendekatan sebagai alternative pemecahan terhadap kesenjangan gender. Kedua pendekatan tersebut adalah pendekatan strategis dan pendekatan praktis terhadap kebutuhan gender. ${ }^{12}$ Kedua pendekatan tersebut sama-sama memperhatikan kebutuhan laki-laki dan perempuan sekaligus dalam mencapai hasil yang lebih efektif yang merupakan salah satu ciri dari teori gender dan pembangunan ini. Pendekatan strategis lebih ditujukan pada usaha-usaha yang dampaknya akan dirasakan dalam jangka waktu yang lebih lama. Misalnya mengubah persepsi yang berbeda terhadap keberadaan IPTEK untuk lebih ramah terhadap perempuan, mengubah kurikulum IPTEK lebih menarik bagi para siswa (laki-laki dan perempuan), pembentukari forum diskusi ilmuawati di Indonesia d11. Sementara pendekatan praktis dapat berupa penyelesaian langsung dari problem sehari-hari yang dialami perempuan. Misalnya ketidakmampuannya dalam mengoperasikan komputer, dapat diatasi dengan kursus kilat komputer, penyediaan komputer oleh lembaga dsb.

Kebijakan IPTEK di Indonesia juga masih memarginalkan perempuan, hal ini karena kebijakan IPTEK yang diambil itu lebih melayani kaum kapital

${ }^{12}$ Ruth Alsop, "Whose interests? Problem in Planning for Women's Practical Needs", dalam World Development, Vol. 21 (3): 367-377. 1993 
seperti kasus kebijakan IPTEK yang sudah diterangkan dimuka. Sehingga nantinya laki-laki terutama perempuan jugalah yang menjadi korbannya karena sebagian besar penduduk miskin didunia adalah berjenis kelamin perempuan. Dengan kemiskinannya dan privatisasi pendidikan di Indonesia maka akses mereka pada pemenuhan hak dalam bidang IPTEK akan semakin jauh dari yang diharapkan.

\section{F. Kesimpulan}

Dengan memperhatikan uraian diatas, maka kesimpulan yang dapat ditarik adalah sebagai berikut :

Sejak jaman pra sejarah sampai saat ini perempuan merupakan bagian tak terpisahkan dari IPTEK meskipun masih terdapat kesenjangan penguasaan IPTEK antara laki-laki dengan perempuan. Dalam memandang kesenjangan ini aliran eko-feminis berbeda pendafat dengan aliran liberal ferninis.

Meskipun secara normatif kebijakan IPTEK di Indonesia sudah netral. gender, tetapi terlihat sangat ambivalen antara keberpihakan terhadap pernenuhan IPTEK bagi rakyat Indonesia atau keberpihakan terhadap rejim kapital. Sayangnya dalam implementasinya, pemerintah lebih mengutamakan kepentingan rejim kapital di segala tingkatan baik ditingkat global maupun nasional, sehingga pemenuhan hak IPTEK bagi laki-laki maupun perempuan di Indonesia semakin sulit terwujud.

Dampak perkembangan IPTEK terhadap perempuan dapat dilihat pada tiap-tiap bidang dimana dapat mempengaruhi relasi gender. Untuk 
meminimalisir dampak negatif terhadap perempuan dan juga laki-laki maka kepentimgan masyarakat harus lebih diutamakan daripada kepentingan pengembangan IPTEK semata.

Perlu konstruksi ulang terhadap konsep maskulinitas versus fernininitas IPTEK dengan mengurangi lebel negatif terhadap konsep femininitas IPTEK dan mernfeminimkan IPTEK yang selama ini membawa dampak negatif terhadap perempuan, dan juga laki-laki.

Untuk mengatasi kesenjangan perempuan dalam IPTEK maka strategi gender harus bersama-sama dipakai dengan strategi untuk merninimalisir kesenjangan kelas dan kapital baik dalam tingkat global maupun nasional. Jika kesenjangan ini tidak berhasil diatasi, maka kesenjangan perempuan dalam bidang IPTEK akan terus berlangsung.

\section{DAFTAR PUSTAKA}

Alsop, R., 1993, "Whose interests? Problem in Planning for Women's Practical Needs", dalam World Development, Vol. 21 (3): 367-377.

Frissen, Valerie, 1995, "Gender is Calling: Some reflections on Past, Present and Future Uses of the Telephone" dalam Grint, Keith and Gill, Rosalind (Penyunting), The Gender-Technology Relation, Taylor and Francis, London, 79-94.

Grint, K. dan Gill, R., 1995, "The Gender-Technology Relation: Contemporary Theory and Research", Taylor and Francis Ltd, London.

Mohsin, Yulianto (terjemah), 2005, "Irene Juliot-Curie: Penemu Radioaktivitas Buatan, (Irenedoliol-Curie", Nobel Pri.:e Women in,3cience”,) oleh McGrayne, Sharon.

Prihatinah, T.L., 1996, "Feminist Analysis of Women Workers in the Export Garmen 'actories of Central Java - Indonesia", thesis S2, Universitas Murdoch, Western Australia. 
Universitas Pretoria, 2005, "Women in Engineering", tersedia di website: littp:HNvw,,v.ee.up.za/department/women_in-eng.htmi, diakses pada 2 Desember 2005.

WaJcman, J., 1991, “Feminism Controls Technology”, Polity, Cambridge. 